\title{
The Effect of Anastomotic Leakage on the Incidence and Severity of Low Anterior Resection Syndrome in Patients Undergoing Proctectomy: A Propensity Score Matching Analysis
}

\author{
Sungjin Kim, Sung Il Kang, So Hyun Kim, Jae-Hwang Kim \\ Department of Surgery, Yeungnam University College of Medicine, Daegu, Korea
}

Purpose: Proctectomy for the treatment of rectal cancer results in inevitable changes to bowel habits. Symptoms such as fecal incontinence, constipation, and tenesmus are collectively referred to as low anterior resection syndrome (LARS). Among the several risk factors that cause LARS, anastomotic leakage (AL) is a strong risk factor for permanent stoma formation. Therefore, the purpose of this study was to investigate the relationship between the severity of LARS and AL in patients with rectal cancer based on the LARS score and the Memorial Sloan Kettering Cancer Center (MSKCC) defecation symptom questionnaires.

Methods: We retrospectively analyzed patients who underwent low anterior resection for rectal cancer since January 2010. Patients who completed the questionnaire were classified into the AL group and control group based on medical and imaging records. Major LARS and MSKCC scores were analyzed as primary endpoints.

Results: Among the 179 patients included in this study, 37 were classified into the AL group. After propensity score matching, there were significant differences in the ratio of major LARS and MSKCC scores of the control group and AL group (ratio of major LARS: $11.1 \%$ and $37.8 \%, \mathrm{P}<0.001$; MSKCC score: $67.29 \pm 10.4$ and $56.49 \pm 7.2$, respectively, $\mathrm{P}<$ 0.001). Univariate and multivariate analyses revealed that AL was an independent factor for major LARS occurrence and MSKCC score.

Conclusion: This study showed that AL was a significant factor in the occurrence of major LARS and defecation symptoms after proctectomy.

Keywords: Proctectomy; Anastomotic leakage; Low anterior resection syndrome; Rectal neoplasms

\section{INTRODUCTION}

Surgical resection is the basic principle of rectal cancer treatment. With advances in surgical techniques, such as total mesorectal ex-

Received: Dec 31, 2020 - Revised: Mar 9, 2021 - Accepted: Mar 15, 2021 Correspondence to: Sung II Kang, M.D.

Department of Surgery, Yeungnam University Medical Center, Yeungnam University College of Medicine, 170 Hyeonchung-ro, Nam-gu, Daegu 42415, Korea

Tel: +82-53-620-3580, Fax: +82-31-787-4055

E-mail: sungiry@naver.com

ORCID: https://orcid.org/0000-0002-4751-5779

(c) 2021 The Korean Society of Coloproctology

This is an open-access article distributed under the terms of the Creative Commons Attribution NonCommercial License (https://creativecommons.org/licenses/by-nc/4.0) which permits unrestricted noncommercial use, distribution, and reproduction in any medium, provided the original work is properly cited. cision, chemotherapy, and radiation therapy, survival rates for rectal cancer have gradually increased, with a 5-year survival rate exceeding $70 \%$ in Korea [1].

However, proctectomy involves inevitable changes in bowel habits, which can impede quality of life. After rectal resection, a series of symptoms occur, including fecal incontinence, constipation, tenesmus, urgency, feeling of incomplete emptying, and frequent bowel movement that are collectively referred to as low anterior resection syndrome (LARS) $[2,3]$. The incidence of LARS varies across studies but is commonly reported in more than half of the patients with rectal resection. According to a cohort study of 961 patients who underwent rectal resection in Denmark, LARS occurs in $64 \%$ of patients with rectal resection; of which, $41 \%$ complained of severe symptoms [4]. LARS symptoms were alleviated 6 months to 1 year postoperatively $[2,5]$. However, there are re- 
ports that about $50 \%$ of patients complain of symptoms, even 15 years postoperatively $[6,7]$. As such, LARS can affect the quality of life over a long period of time.

Various factors affect the incidence and severity of LARS. Representative risk factors include preoperative radiotherapy, anastomosis near the anal verge, end-to-end anastomosis without a pouch, and anastomotic leakage (AL) [3]. Of these, AL is a complication reported in about $20 \%$ of patients who underwent endto-end anastomosis after rectal resection $[8,9]$ and is a strong risk factor for permanent stoma formation [10]. Nevertheless, due to patients' rejection of permanent stoma or a burden on the operator, the operator maintains the continuity of the intestinal tract, except in inevitable cases, such as sepsis due to AL. However, from a long-term perspective, this can worsen the quality of life of patients.

Several studies have been conducted on AL associated with LAR, and methods to prevent this have also been demonstrated $[9,11]$. However, few studies have investigated the association between AL and LARS, and especially in Korea, even though the incidence of LARS has not been properly investigated [12]. There are no clinical studies that prove inflammatory reactions, such as fibrotic scar or chronic sinus, induced by AL cause deterioration of the remnant rectum and lead to LARS. If the association between LARS and AL is proven through research, the rationale for this would be that preventing AL can prevent the occurrence of LARS. Therefore, the purpose of this study was to investigate the relationship between AL and the severity of LARS in patients with rectal cancer.

\section{METHODS}

Patients who underwent low anterior resection for rectal cancer from January 2010 to September 2019 at Yeungnam University Medical Center in Daegu, Korea were reviewed retrospectively. Low anterior resection was performed by an experienced colorectal surgeon. At the time of investigation, the study was performed on patients who underwent surgery more than 1 year before. The exclusion criteria were (1) permanent or temporary ostomy at the time of investigation, (2) patients who underwent colon resection or small bowel resection of $>100 \mathrm{~cm}$ or gastrectomy in addition to low anterior resection, (3) patients with cognitive or mental disabilities who lack the ability to understand the questionnaire and respond properly, and (4) patients who disagree with the study or have lost contact with the study investigators. If patients did not visit the hospital after follow-up was completed, the researchers explained the study details through telephonic conversations, and if patients agreed, they could visit the hospital at the desired time and complete the questionnaire.

The Korean version of the LARS score questionnaire [13] was used, and the scores were converted according to each item. The sum of the scores of each item was classified as follows: 0 to 20, no LARS; 21 to 29, minor LARS; 30 to 42, major LARS. The items of the Memorial Sloan Kettering Cancer Center (MSKCC) [14] questionnaire were translated to Korean. The scores of the 1st, 4 th, 5th, 7th, 11th, and 12th items were recalculated because a higher score represents a more severe defecation problem. We evaluated the defecation symptom as the sum of the scores for each item, indicating that the higher the score, the better the defecation function.

In this study, AL is defined as defects in the intestinal wall of the anastomosis site, and determined based on medical and imaging records and classified as follows based on the classification system commonly used in clinical practice [15]: grade A leakage requires no therapeutic intervention, and does not affect a patient's management; grade $\mathrm{B}$ leakage requires active therapeutic intervention, but is manageable without reoperation; and grade $\mathrm{C}$ leakage requires reoperation. Clinically, AL signs were defined as fever, abdominal pain, fecal discharge from a drain, peritoneal irritation sign, and pelvic abscess postoperatively. All clinically diagnosed ALs were confirmed by digital rectal examination or computed tomography. The medical records of patients who completed the questionnaire were analyzed retrospectively and classified into the AL group (grade B, C) and control group (no AL, grade A).

To minimize the effect of confounders on selection bias, propensity score and nearest-neighbor matching (PSM) analyses were performed. Patients in the AL group were matched on a 1:2 propensity score with patients in the control group according to age, sex, body mass index, tumor location, neoadjuvant treatment, surgical approach, operative method, anastomosis type, and fecal diversion.

Baseline demographics were compared between the AL and control groups. The Student t-test or Mann-Whitney U-test was used for continuous variables; and for categorical variables, a chisquare test or Fisher exact test was used. Univariate analyses were performed to identify factors associated with the LARS and MSKCC total scores by using logistic regression and linear regression analyses. Variables with P-values of $<0.05$ in univariate analyses were included in the multivariate analyses. All statistical analyses were considered significant at $\mathrm{P}<0.05$. Statistical analysis was performed using IBM SPSS Statistics ver. 22.0 (IBM Corp., Armonk, NY, USA).

This study was approved by the Institutional Review Board of Yeungnam University Medical Center (No. YUMC 2020-03-117007) with the written informed consent from the patients.

\section{RESULTS}

A survey including the LARS score and MSKCC defecation symptom questionnaires was conducted between November 2019 and September 2020. A total of 208 patients met the selection criteria. Patients who were scheduled to visit our institution for the treatment or follow-up of rectal cancer answered the questionnaire after the explanation of the researcher. Of the 208 patients, 179 answered the questionnaire (Fig. 1). 


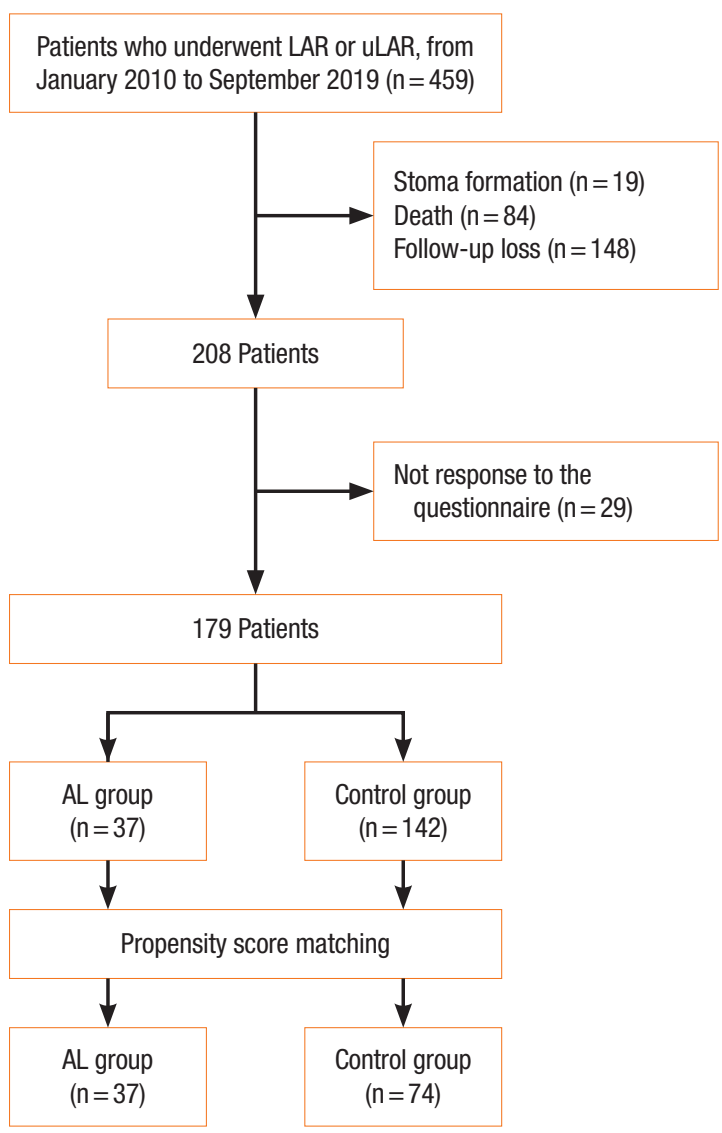

Fig. 1. Flow chart of study patients. LAR, low anterior resection; ULAR, ultra low anterior resection; AL, anastomotic leakage.

Among the 179 patients, 23 patients (12.8\%) had grade B leakage and $14(7.8 \%)$ had grade $\mathrm{C}$ leakage. A total of 37 patients with grade $\mathrm{B}$ and $\mathrm{C}$ leakage were classified into the $\mathrm{AL}$ group and the remaining 142 patients were classified into the control group.

There was no difference in baseline characteristics between the 2 groups (Table 1). By performing PSM, 74 out of 142 patients in the control group were matched. There was no difference between the 2 groups except for the time to surgery factor after PSM. Before and after PSM, the LARS and MSKCC scores were significantly different between the control group and AL group (LARS score [before matching]: $14.60 \pm 12.6$ and $28.30 \pm 6.4, \mathrm{P}<0.001$; LARS score [after matching]: $15.62 \pm 13.0$ and $28.30 \pm 6.4, \mathrm{P}<$ 0.001; MSKCC score [before matching]: $66.88 \pm 9.1$ and $55.24 \pm$ 7.0, $\mathrm{P}<0.001$; MSKCC score [after matching]: $66.63 \pm 8.5$ and $55.24 \pm 7.0, \mathrm{P}<0.001)$. Moreover, the ratio of major LARS was significantly higher in the AL group (control group and AL group; before matching: $12.7 \%$ and $37.8 \%, \mathrm{P}<0.001$; after matching: $13.5 \%$ and $37.8 \%, \mathrm{P}<0.001$ ).

Before PSM, univariate analysis showed that major LARS was associated with neoadjuvant therapy, tumor stage, and grade B and C AL. After PSM, neoadjuvant therapy, fecal diversion, tumor stage, and grade B and C AL were significant factors with major LARS in the univariate analysis (Table 2). Multivariate analysis demonstrated that grade $\mathrm{B}$ and $\mathrm{C} \mathrm{AL}$ and neoadjuvant therapy were independent factors for major LARS (Table 3).

The same analysis was conducted to identify the independent factor for the MSKCC score. Before PSM, grade B and C AL were independent factors for MSKCC score in univariate analysis. Sex, tumor location, and grade $\mathrm{B}$ and $\mathrm{C} \mathrm{AL}$ were independent factors for MSKCC in the univariate analysis after PSM (Table 4). The multivariate analysis showed that sex, tumor location, and grade $\mathrm{B}$ and C AL were significantly associated with MSKCC score (Table 5).

The LARS score and MSKCC scores have an inverse relation, which forms a significant $(\mathrm{P}<0.001)$ correlation graph $($ Fig. 2$)$. And the LARS and MSKCC scores were the same in both fecal diversion device (FDD) and loop ileostomy groups (Table 6).

\section{DISCUSSION}

Our study findings showed that AL and neoadjuvant chemoradiotherapy affected LARS and defecation symptoms in patients with rectal cancer who underwent LAR. These results are comparable to those of previous studies that also evaluated the factor which affect LARS and defecation symptoms $[4,16,17]$.

The exact diagnosis and approach to LARS depend on asking appropriate questions about the patient's symptoms. According to a recent meta-analysis, due to the lack of a LARS definition, longterm bowel function was not evaluated, and in $65 \%$ of studies, a validated questionnaire was not used [18]. The surveys for investigating the quality of life that have been published are very diverse and complex; therefore, it takes a long time to complete and analyze them. It has also been reported that they represent specific symptoms and are not suitable for collecting complex symptoms associated with bowel movements and reflecting the quality of life associated with bowel movements [19].

According to several studies, there are a number of factors that worsen LARS, such as radiotherapy, the extent of rectal excision, the creation of a colonic pouch, and AL. In this study, we focused on AL, a deteriorating factor of LARS. Since there are many factors that affect LARS among the risk factors of AL, such as low-lying tumor and preoperative chemoradiation, correction between the leak group and the no-leak group was performed through PSM. Regarding the impact of postoperative AL on defecation symptoms, there are not much available data and a somewhat heterogeneous investigation of symptoms. There are also few studies on the histological approach of AL. Daams et al. [20] showed that the healing of gastrointestinal anastomosis in an experimental model occurred by the formation of a fibrotic cap at the serosal portion, which formed a matrix for fibroblasts. Based on this result, $\mathrm{AL}$ occurrence is considered a negative event for bowel function because of the inflammatory change and excessive fibrotic scarring that may develop thereafter in the pelvic cavity. 
The Effect of Anastomotic Leakage on the Incidence and Severity of Low Anterior Resection Annals of Syndrome in Patients Undergoing Proctectomy: A Propensity Score Matching Analysis

\section{Coloproctology sungin Kim, et al.}

Table 1. Comparison of characteristics before and after propensity score matching

\begin{tabular}{|c|c|c|c|c|c|c|}
\hline \multirow{2}{*}{ Characteristic } & \multicolumn{3}{|c|}{ Before matching } & \multicolumn{3}{|c|}{ After matching } \\
\hline & AL group $(n=37)$ & Control group $(n=142)$ & P-value & AL group $(n=37)$ & Control group $(n=74)$ & P-value \\
\hline Age (yr) & & & 0.343 & & & 0.308 \\
\hline$\geq 70$ & $9(24.3)$ & $46(32.4)$ & & $9(24.3)$ & 25 (33.8) & \\
\hline$<70$ & $28(75.7)$ & $96(67.6)$ & & $28(75.7)$ & $49(66.2)$ & \\
\hline Sex & & & 0.693 & & & 0.272 \\
\hline Male & $25(67.6)$ & $91(64.1)$ & & $25(67.6)$ & $42(56.8)$ & \\
\hline Female & $12(32.4)$ & $51(35.9)$ & & $12(32.4)$ & $32(43.2)$ & \\
\hline BMI $\left(\mathrm{kg} / \mathrm{m}^{2}\right)$ & & & 0.429 & & & 0.069 \\
\hline$\leq 25$ & $28(75.7)$ & $98(69.0)$ & & $28(75.7)$ & $43(58.1)$ & \\
\hline$>25$ & $9(24.3)$ & $44(31.0)$ & & $9(24.3)$ & $31(41.9)$ & \\
\hline Time after surgery (yr) & & & 0.089 & & & 0.003 \\
\hline$\leq 2$ & $9(24.3)$ & $56(39.4)$ & & $9(24.3)$ & $40(54.1)$ & \\
\hline$>2$ & $28(75.7)$ & $86(60.6)$ & & $28(75.7)$ & $34(45.9)$ & \\
\hline Tumor location & & & 0.737 & & & 0.608 \\
\hline Upper rectum & $11(29.7)$ & $52(36.6)$ & & $11(29.7)$ & 29 (39.2) & \\
\hline Mid rectum & $15(40.5)$ & $52(36.6)$ & & $15(40.5)$ & 27 (36.5) & \\
\hline Lower rectum & $11(29.7)$ & $38(26.8)$ & & $11(29.7)$ & 18 (24.3) & \\
\hline Neoadjuvant therapy & & & 0.553 & & & 0.476 \\
\hline No & 32 (86.5) & $117(82.4)$ & & 32 (86.5) & 60 (81.1) & \\
\hline Yes & $5(13.5)$ & $25(17.6)$ & & 5 (13.5) & $14(18.9)$ & \\
\hline Surgical approach & & & 0.414 & & & 0.419 \\
\hline Open & $6(16.2)$ & $16(11.3)$ & & $6(16.2)$ & $8(10.8)$ & \\
\hline Laparoscopic & $31(83.8)$ & $126(88.7)$ & & $31(83.8)$ & 66 (89.2) & \\
\hline Operative method & & & 0.932 & & & 0.722 \\
\hline LAR & $30(81.1)$ & $116(81.7)$ & & 30 (81.1) & $62(83.8)$ & \\
\hline uLAR & 7 (18.9) & 26 (18.3) & & 7 (18.9) & $12(16.2)$ & \\
\hline Anastomotic type & & & 0.942 & & & 1.000 \\
\hline Stapled end to end & $34(91.9)$ & $131(92.3)$ & & $34(91.9)$ & $68(91.9)$ & \\
\hline Handsewn end to end & $3(8.1)$ & $11(7.7)$ & & $3(8.1)$ & $6(8.1)$ & \\
\hline Fecal diversion & & & 0.936 & & & 0.967 \\
\hline No & $13(35.1)$ & $50(35.2)$ & & $13(35.1)$ & $30(40.5)$ & \\
\hline FDD & $11(31.8)$ & $46(32.4)$ & & $11(31.8)$ & $23(31.1)$ & \\
\hline Loop ileostomy & $13(35.2)$ & $46(32.4)$ & & $13(35.1)$ & $21(28.4)$ & \\
\hline IMA ligation & & & 0.697 & & & 0.773 \\
\hline High & $26(70.3)$ & $95(66.9)$ & & $26(70.3)$ & $50(67.6)$ & \\
\hline Low & $11(29.7)$ & $47(33.1)$ & & $11(29.7)$ & $24(32.4)$ & \\
\hline Tumor stage & & & 0.678 & & & 0.490 \\
\hline 1 & 7 (18.9) & $34(23.9)$ & & 7 (18.9) & $20(27.0)$ & \\
\hline$\|$ & $10(27.0)$ & $33(23.2)$ & & $10(27.0)$ & $12(16.2)$ & \\
\hline III & $17(45.9)$ & $54(38.0)$ & & $17(45.9)$ & $31(41.9)$ & \\
\hline IV & $3(8.1)$ & $21(14.8)$ & & $3(8.1)$ & $11(14.9)$ & \\
\hline LARS score & $28.30 \pm 6.4$ & $14.60 \pm 12.6$ & $<0.001$ & $28.30 \pm 6.4$ & $15.62 \pm 13.0$ & $<0.001$ \\
\hline
\end{tabular}


Table 1. Continued

\begin{tabular}{|c|c|c|c|c|c|c|}
\hline \multirow{2}{*}{ Characteristic } & \multicolumn{3}{|c|}{ Before matching } & \multicolumn{3}{|c|}{ After matching } \\
\hline & AL group $(n=37)$ & Control group $(n=142)$ & P-value & AL group $(n=37)$ & Control group $(n=74)$ & P-value \\
\hline LARS classification & & & $<0.001$ & & & $<0.001$ \\
\hline No & $2(5.4)$ & $86(60.6)$ & & $2(5.4)$ & $42(56.8)$ & \\
\hline Mild & $21(56.8)$ & $38(26.8)$ & & $21(56.8)$ & $22(29.7)$ & \\
\hline Major & $14(37.8)$ & $18(12.7)$ & & $14(37.8)$ & 10 (13.5) & \\
\hline MSKCC score & $55.24 \pm 7.0$ & $66.88 \pm 9.1$ & $<0.001$ & $55.24 \pm 7.0$ & $66.63 \pm 8.5$ & $<0.001$ \\
\hline
\end{tabular}

Values are expressed as mean \pm standard deviation or number (\%).

$\mathrm{AL}$, anastomotic leakage; BMI, body mass index; LAR, low anterior resection; ULAR, ultra low anterior resection; FDD, fecal diversion device; IMA, inferior mesenteric artery; LARS, low anterior resection syndrome; MSKCC, Memorial Sloan Kettering Cancer Center.

Table 2. Univariate analysis of risk factors for major LARS

\begin{tabular}{|c|c|c|c|c|c|c|c|c|}
\hline \multirow{2}{*}{ Factor } & \multirow{2}{*}{$\begin{array}{c}\text { Incidence of } \\
\text { major LARS (\%) }\end{array}$} & \multicolumn{3}{|c|}{ Before matching } & \multirow{2}{*}{$\begin{array}{l}\text { Incidence of } \\
\text { major LARS (\%) }\end{array}$} & \multicolumn{3}{|c|}{ After matching } \\
\hline & & P-value & Odds ratio & $95 \% \mathrm{Cl}$ & & P-value & Odds ratio & $95 \% \mathrm{Cl}$ \\
\hline
\end{tabular}

Age (yr)

$\leq 70$

$>70$

19.4

16.4

17.2

Male

Female

20.6

0.763

0.725

1
0.859

$0.369-2.002$

23.4

20.6

23.9

20.5

1.129

$0.511-2.494$

16.7

22.6

0.515

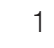

1.310

$0.581-2.951$

21.1

25.0

18.4

25.8

0.512

1.315

$0.580-2.982$

12.5

28.2

0.357

1.484

0.640-3.439

14.1

40.0

0.005

1

3.529

1.472-8.459

17.4

47.4

42.9

Open

27.3

Laparoscopic

17.2

0.225

1

Operative method

LAR

ULAR

17.1

24.2

0.581

1

1.303

0.509-3.333

36.8

19.6

0.189-1.480

17.6

28.6

0.284

1

1.957

0.573-6.687

20.6

44.4

0.115

3.068

0.761-12.509 


\section{Coloproctology Sungjin Kim, et al.}

Table 2. Continued

\begin{tabular}{|c|c|c|c|c|c|c|c|c|}
\hline \multirow{2}{*}{ Factor } & \multirow{2}{*}{$\begin{array}{l}\text { Incidence of } \\
\text { major LARS (\%) }\end{array}$} & \multicolumn{3}{|c|}{ Before matching } & \multirow{2}{*}{$\begin{array}{c}\text { Incidence of } \\
\text { major LARS (\%) }\end{array}$} & \multicolumn{3}{|c|}{ After matching } \\
\hline & & P-value & Odds ratio & $95 \% \mathrm{Cl}$ & & P-value & Odds ratio & $95 \% \mathrm{Cl}$ \\
\hline \multicolumn{9}{|l|}{ Fecal diversion } \\
\hline No & 12.7 & & 1 & & 9.3 & & 1 & \\
\hline Yes & 21.6 & 0.187 & 1.793 & $0.754-4.268$ & 30.9 & 0.012 & 4.356 & $1.379-13.764$ \\
\hline \multicolumn{9}{|l|}{ IMA ligation } \\
\hline High & 20.7 & & 1 & & 25.0 & & 1 & \\
\hline Low & 13.8 & 0.326 & 0.647 & $0.271-1.543$ & 17.1 & 0.360 & 0.621 & $0.224-1.723$ \\
\hline \multicolumn{9}{|l|}{ Tumor stage } \\
\hline$|\&| \mid$ & 11.9 & & 1 & & 12.2 & & 1 & \\
\hline III \& IV & 24.2 & 0.037 & 2.364 & $1.051-5.315$ & 30.6 & 0.025 & 3.167 & 1.153-8.699 \\
\hline \multicolumn{9}{|c|}{ Anastomotic leakage } \\
\hline No \& grade A & 12.7 & & 1 & & 13.5 & & 1 & \\
\hline Grade B, C & 40.5 & 0.001 & 4.193 & $1.832-9.598$ & 40.5 & 0.002 & 4.364 & $1.713-11.119$ \\
\hline
\end{tabular}

LARS, low anterior resection syndrome; Cl, confidence interval; BMI, body mass index; LAR, low anterior resection; ULAR, ultra low anterior resection; IMA, inferior mesenteric artery.

Table 3. Multivariate analysis of risk factors for major LARS

\begin{tabular}{|c|c|c|c|c|c|c|}
\hline \multirow{2}{*}{ Factor } & \multicolumn{3}{|c|}{ Before matching } & \multicolumn{3}{|c|}{ After matching } \\
\hline & P-value & Odds ratio & $95 \% \mathrm{Cl}$ & P-value & Odds ratio & $95 \% \mathrm{Cl}$ \\
\hline \multicolumn{7}{|c|}{ Neoadjuvant therapy } \\
\hline No & & 1 & & & 1 & \\
\hline Yes & 0.001 & 4.960 & $1.886-13.042$ & 0.026 & 4.235 & $1.189-15.087$ \\
\hline \multicolumn{7}{|l|}{ Fecal diversion } \\
\hline No & NA & NA & NA & & 1 & \\
\hline Yes & NA & NA & NA & 0.077 & 3.096 & $0.884-10.837$ \\
\hline \multicolumn{7}{|l|}{ Tumor stage } \\
\hline$|\&| \mid$ & & 1 & & & 1 & \\
\hline III \& IV & 0.079 & 2.195 & $0.914-5.270$ & 0.053 & 3.048 & $0.986-9.422$ \\
\hline \multicolumn{7}{|c|}{ Anastomotic leakage } \\
\hline No \& grade $A$ & & 1 & & & 1 & \\
\hline Grade B, C & $<0.001$ & 6.129 & $2.471-15.200$ & 0.001 & 6.396 & $2.110-19.389$ \\
\hline
\end{tabular}

LARS, low anterior resection syndrome; $\mathrm{Cl}$, confidence interval; NA, not applicable.

This can alter compliance and the capacity of the neorectum, which can induce urgency or incontinence.

If neoadjuvant therapy was performed, surgery was performed 6 weeks after the end of neoadjuvant therapy. Therefore, it can be seen that LARS is worsened by ischemia and fibrosis caused by progressive obliterating endarteritis and the late toxicity of radiotherapy. Gastrointestinal tract ulceration causes symptoms such as perforation, fistulization, and peritonitis, and is associated with an extensive area of fibrosis [21]. Anal sphincter damage is also induced by radiotherapy, which is due to the damage to the myenteric plexus and smooth-muscle hypertrophy [22]. The length of the residual rectum on magnetic resonance imaging affects LARS severity, and it is reported that LARS severity is high when the length of the residual rectum is less than $4 \mathrm{~cm}$ [23].

Reduced neorectal reservoir volume is considered a major cause of urgency or incontinence. According to several studies, low-lying tumors or anastomoses of $<5 \mathrm{~cm}$ from the anal verge are independent risk factors for deteriorated defecation symptoms [17, 23]. Damage to the internal anal sphincter during rectal mobilization causes passive incontinence [24], and damage to the pelvic floor innervations leads to fecal incontinence and urgency [25]. Moreover, a decrease in the length of the urethral rectum leads to 
Table 4. Univariate analysis of risk factors for MSKCC score

\begin{tabular}{|c|c|c|c|c|c|c|}
\hline \multirow{2}{*}{ Factor } & \multicolumn{3}{|c|}{ Before matching } & \multicolumn{3}{|c|}{ After matching } \\
\hline & $B(\beta)$ & P-value & $95 \% \mathrm{Cl}$ for $\mathrm{B}$ & $B(\beta)$ & P-value & $95 \% \mathrm{Cl}$ for $\mathrm{B}$ \\
\hline \multicolumn{7}{|l|}{ Age (yr) } \\
\hline \multicolumn{7}{|l|}{$\leq 70$} \\
\hline$>70$ & $-0.856(-0.040)$ & 0.596 & -4.035 to 2.323 & $-0.290(-0.014)$ & 0.885 & -4.240 to 3.661 \\
\hline \multicolumn{7}{|l|}{ Sex } \\
\hline Female & $2.831(0.137)$ & 0.068 & -0.214 to 5.876 & $4.023(0.205)$ & 0.031 & 0.379 to 7.666 \\
\hline \multicolumn{7}{|l|}{ BMI $\left(\mathrm{kg} / \mathrm{m}^{2}\right)$} \\
\hline \multicolumn{7}{|l|}{$<25$} \\
\hline$\geq 25$ & $-1.184(-0.055)$ & 0.468 & -4.394 to 2.026 & $0.163(0.008)$ & 0.932 & -3.630 to 3.956 \\
\hline \multicolumn{7}{|l|}{ Time from surgery (yr) } \\
\hline \multicolumn{7}{|l|}{ Upper rectum } \\
\hline Mid \& lower rectum & $-2.807(-0.135)$ & 0.071 & -5.852 to 0.239 & $-4.208(-0.211)$ & 0.027 & -7.916 to -0.500 \\
\hline \multicolumn{7}{|l|}{ Neoadjuvant therapy } \\
\hline \multicolumn{7}{|l|}{ No } \\
\hline Yes & $-1.512(-0.057)$ & 0.448 & -5.435 to 2.412 & $0.423(0.017)$ & 0.863 & -4.411 to 5.258 \\
\hline \multicolumn{7}{|l|}{ Surgical approach } \\
\hline \multicolumn{7}{|l|}{ Laparoscopic } \\
\hline Open & $1.268(0.084)$ & 0.263 & -0.959 to 3.496 & $1.560(0.108)$ & 0.259 & -1.167 to 4.287 \\
\hline \multicolumn{7}{|l|}{ Operative method } \\
\hline \multicolumn{7}{|l|}{ LAR } \\
\hline \multicolumn{7}{|l|}{ Anastomotic type } \\
\hline \multicolumn{7}{|l|}{ Fecal diversion } \\
\hline \multicolumn{7}{|l|}{ No } \\
\hline Yes & $1.713(0.083)$ & 0.271 & -1.350 to 4.775 & 1.019 (0.052) & 0.590 & -2.715 to 4.752 \\
\hline \multicolumn{7}{|l|}{ IMA ligation } \\
\hline \multicolumn{7}{|l|}{ High } \\
\hline Low & $1.695(0.080)$ & 0.286 & -1.431 to 4.821 & $2.622(0.127)$ & 0.184 & -1.266 to 0.650 \\
\hline Tumor stage & & & & & & \\
\hline$|\&| \mid$ & & & & & & \\
\hline III \& IV & $-0.541(-0.027)$ & 0.717 & -3.481 to 2.399 & $1.510(0.078)$ & 0.415 & -2.146 to 5.167 \\
\hline Anastomotic leakage & & & & & & \\
\hline No \& grade A & & & & & & \\
\hline Grade B, C & $-11.637(-0.476)$ & $<0.001$ & -14.824 to -8.450 & $-11.385(-0.559)$ & $<0.001$ & -14.587 to -8.183 \\
\hline
\end{tabular}

MSKCC, Memorial Sloan Kettering Cancer Center; Cl, confidence interval; BMI, body mass index; LAR, low anterior resection; uLAR, ultra low anterior resection; IMA, inferior mesenteric artery.

$B=$ unstandardized coefficients, $\beta$ =standardized $\beta$-coefficient. 


\section{Coloproctology sungjin $\mathrm{Kim}$, et al.}

Table 5. Multivariate analysis of risk factors for MSKCC score

\begin{tabular}{|c|c|c|c|c|c|c|}
\hline \multirow{2}{*}{ Factor } & \multicolumn{3}{|c|}{ Before matching } & \multicolumn{3}{|c|}{ After matching } \\
\hline & $B(\beta)$ & P-value & $95 \% \mathrm{Cl}$ for $\mathrm{B}$ & $B(\beta)$ & P-value & $95 \% \mathrm{Cl}$ for $\mathrm{B}$ \\
\hline \multicolumn{7}{|l|}{ Sex } \\
\hline Female & NA & NA & NA & $3.500(0.178)$ & 0.024 & 0.459 to 6.540 \\
\hline \multicolumn{7}{|l|}{ Tumor location } \\
\hline \multicolumn{7}{|l|}{ Anastomotic leakage } \\
\hline No \& grade $A$ & & Reference & & & & \\
\hline Grade B, C & $-11.637(-0.476)$ & $<0.001$ & -14.824 to -8.450 & $-10.651(-0.523)$ & $<0.001$ & -13.784 to -7.517 \\
\hline
\end{tabular}

MSKCC, Memorial Sloan Kettering Cancer Center; Cl, confidence interval; NA, not applicable.

$\mathrm{B}=$ unstandardized coefficients, $\beta=$ standardized $\beta$-coefficient.

Table 6. Comparison of LARS score and MSKCC score according to fecal diversion method

\begin{tabular}{|c|c|c|c|c|c|c|}
\hline \multirow[b]{2}{*}{ Factor } & \multicolumn{3}{|c|}{ Before matching } & \multicolumn{3}{|c|}{ After matching } \\
\hline & $\begin{array}{l}\text { Loop ileostomy } \\
\quad(n=59)\end{array}$ & $\begin{array}{c}\text { FDD } \\
(n=57)\end{array}$ & P-value & $\begin{array}{l}\text { Loop ileostomy } \\
\qquad(\mathrm{n}=34)\end{array}$ & $\begin{array}{c}\text { FDD } \\
(n=34)\end{array}$ & P-value \\
\hline LARS score & $18.00 \pm 12.84$ & $17.75 \pm 12.67$ & 0.918 & $22.65 \pm 11.56$ & $19.82 \pm 13.29$ & 0.353 \\
\hline MSKCC score & $64.43 \pm 10.18$ & $65.74 \pm 9.04$ & 0.464 & $61.86 \pm 9.30$ & $64.59 \pm 9.17$ & 0.229 \\
\hline
\end{tabular}

Values are presented as mean \pm standard deviation.

LARS, low anterior resection syndrome; MSKCC, Memorial Sloan Kettering Cancer Center; FDD, fecal diversion device.
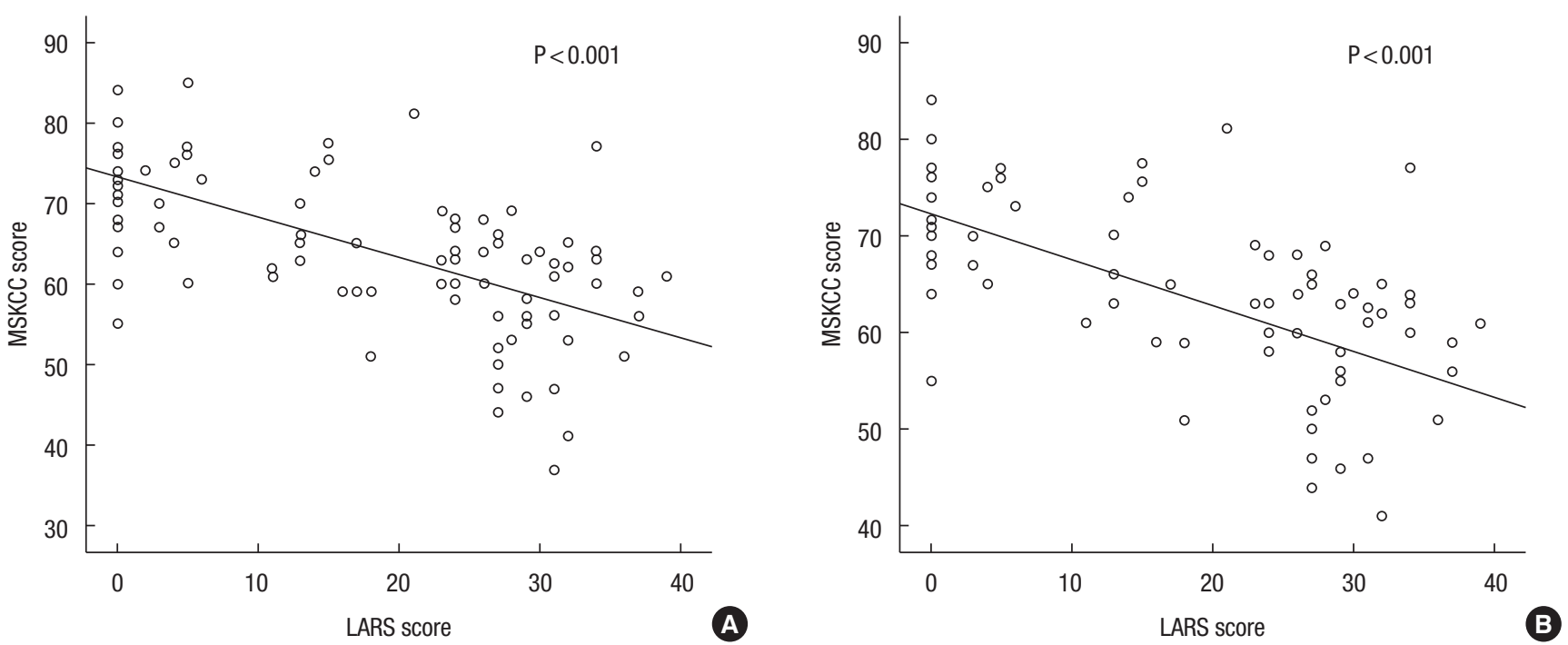

Fig. 2. Graph of correlation between low anterior resection syndrome (LARS) score and Memorial Sloan Kettering Cancer Center (MSKCC) score. (A) Before propensity score matching (PSM). (B) After PSM.

a decrease in neorectal capacity, which leads to a worsening of bowel dysfunction [26].

In our study, female patients showed better bowel function than male patients. To date, there have been no studies that have stud- ied the relationship between bowel dysfunction after low anterior resection and sex difference. The result of our study is expected to be due to the anatomical difference of the pelvis, which is related to the difficulty of surgery. Females had a significantly longer pel- 
vic inlet and outlet, while males had a greater pelvic depth [27]. Therefore, female patients will experience less nerve damage during surgery, and bowel function postoperatively is expected to be better than that of male patients. However, a larger study is needed to confirm this.

In addition to loop ileostomy, which is the traditional method of fecal diversion, patients who performed fecal diversion using the FDD [28], which is being clinically tested at our hospital, are included. In the clinical trial at that time, it was concluded that the ratio of AL between the patient group who underwent ileostomy and the patient group using FDD was the same; hence, it was decided to include patients who used FDD in this study. As was mentioned in the results section, there was no significant difference in LARS score and MSKCC score between the FDD group and the loop ileostomy groups. Therefore, FDD and loop ileostomy were considered as the same fecal diversion method when performing univariate and multivariate analyses.

This study has several limitations. First, it is a nonrandomized study design. Operators must do their best to prevent AL occurrence, and there cannot be a study design that randomizes AL occurrence. Since patients were classified into 2 groups according to the presence or absence of AL, selection bias may occur regarding factors that may cause AL. Thus, the author implemented the PSM method to compensate for the selection bias. For more effective matching, the number of patients should be greater than in this study. Therefore, prospective multicenter research is needed. Second, this is a study based on a survey; since the questionnaire survey is conducted based on the subjective symptoms of the patient, it may be difficult to use it as an objective indicator, and as the survey is mainly conducted on elderly patients, it is difficult to expect accurate memories. Third, the time of the questionnaire survey from surgery was different for each patient. Since LARS shows a trend of improvement from 1 year postoperatively, studies were conducted on patients who underwent operation for more than 1 year, but many studies have shown that symptoms persist for up to 2 years postoperatively. Therefore, it is necessary to investigate defecation symptoms or LARS at several time points, not at 1-time point postoperatively.

In conclusion, this study showed that AL is a risk factor for major LARS and changes in defecation function after low anterior resection and neoadjuvant chemoradiotherapy. Further prospective multicenter studies are needed to confirm the negative prognostic factors of AL and the relationship with major LARS.

\section{CONFLICT OF INTEREST}

No potential conflict of interest relevant to this article was reported.

\section{REFERENCES}

1. Allemani C, Matsuda T, Di Carlo V, Harewood R, Matz M, Nikšić
M, et al. Global surveillance of trends in cancer survival 2000-14 (CONCORD-3): analysis of individual records for $37513025 \mathrm{pa}-$ tients diagnosed with one of 18 cancers from 322 populationbased registries in 71 countries. Lancet 2018;391:1023-75.

2. Bryant CL, Lunniss PJ, Knowles CH, Thaha MA, Chan CL. Anterior resection syndrome. Lancet Oncol 2012;13:e403-8.

3. Sarcher T, Dupont B, Alves A, Menahem B. Anterior resection syndrome: what should we tell practitioners and patients in 2018 ? J Visc Surg 2018;155:383-91.

4. Emmertsen KJ, Laurberg S. Low anterior resection syndrome score: development and validation of a symptom-based scoring system for bowel dysfunction after low anterior resection for rectal cancer. Ann Surg 2012;255:922-8.

5. Martellucci J, Sturiale A, Bergamini C, Boni L, Cianchi F, Coratti A, et al. Role of transanal irrigation in the treatment of anterior resection syndrome. Tech Coloproctol 2018;22:519-27.

6. Chen TY, Wiltink LM, Nout RA, Meershoek-Klein Kranenbarg E, Laurberg S, Marijnen CA, et al. Bowel function 14 years after preoperative short-course radiotherapy and total mesorectal excision for rectal cancer: report of a multicenter randomized trial. Clin Colorectal Cancer 2015;14:106-14.

7. Sturiale A, Martellucci J, Zurli L, Vaccaro C, Brusciano L, Limongelli $\mathrm{P}$, et al. Long-term functional follow-up after anterior rectal resection for cancer. Int J Colorectal Dis 2017;32:83-8.

8. Jannasch O, Klinge T, Otto R, Chiapponi C, Udelnow A, Lippert $\mathrm{H}$, et al. Risk factors, short and long term outcome of anastomotic leaks in rectal cancer. Oncotarget 2015;6:36884-93.

9. Zhang W, Lou Z, Liu Q, Meng R, Gong H, Hao L, et al. Multicenter analysis of risk factors for anastomotic leakage after middle and low rectal cancer resection without diverting stoma: a retrospective study of 319 consecutive patients. Int J Colorectal Dis 2017;32:1431-7.

10. Kim MJ, Kim YS, Park SC, Sohn DK, Kim DY, Chang HJ, et al. Risk factors for permanent stoma after rectal cancer surgery with temporary ileostomy. Surgery 2016;159:721-7.

11. Park JS, Choi GS, Kim SH, Kim HR, Kim NK, Lee KY, et al. Multicenter analysis of risk factors for anastomotic leakage after laparoscopic rectal cancer excision: the Korean laparoscopic colorectal surgery study group. Ann Surg 2013;257:665-71.

12. Ihn MH, Kang SB, Kim DW, Oh HK, Lee SY, Hong SM. Risk factors for bowel dysfunction after sphincter-preserving rectal cancer surgery: a prospective study using the Memorial Sloan Kettering Cancer Center bowel function instrument. Dis Colon Rectum 2014;57:958-66.

13. Kim CW, Jeong WK, Son GM, Kim IY, Park JW, Jeong SY, et al. Validation of Korean version of Low Anterior Resection Syndrome Score Questionnaire. Ann Coloproctol 2020;36:83-7.

14. Temple LK, Bacik J, Savatta SG, Gottesman L, Paty PB, Weiser $\mathrm{MR}$, et al. The development of a validated instrument to evaluate bowel function after sphincter-preserving surgery for rectal cancer. Dis Colon Rectum 2005;48:1353-65.

15. Rahbari NN, Weitz J, Hohenberger W, Heald RJ, Moran B, Ulrich 
A, et al. Definition and grading of anastomotic leakage following anterior resection of the rectum: a proposal by the International Study Group of Rectal Cancer. Surgery 2010;147:339-51.

16. Wells CI, Vather R, Chu MJ, Robertson JP, Bissett IP. Anterior resection syndrome: a risk factor analysis. J Gastrointest Surg 2015; 19:350-9.

17. Battersby NJ, Juul T, Christensen P, Janjua AZ, Branagan G, Emmertsen KJ, et al. Predicting the risk of bowel-related quality-oflife impairment after restorative resection for rectal cancer: a multicenter cross-sectional study. Dis Colon Rectum 2016;59: 270-80.

18. Scheer AS, Boushey RP, Liang S, Doucette S, O'Connor AM, Moher $\mathrm{D}$. The long-term gastrointestinal functional outcomes following curative anterior resection in adults with rectal cancer: a systematic review and meta-analysis. Dis Colon Rectum 2011;54: 1589-97.

19. Chen TY, Emmertsen KJ, Laurberg S. What are the best questionnaires to capture anorectal function after surgery in rectal cancer? Curr Colorectal Cancer Rep 2015;11:37-43.

20. Daams F, Monkhorst K, van den Broek J, Slieker JC, Jeekel J, Lange JF. Local ischaemia does not influence anastomotic healing: an experimental study. Eur Surg Res 2013;50:24-31.

21. Carr ND, Pullen BR, Hasleton PS, Schofield PF. Microvascular studies in human radiation bowel disease. Gut 1984;25:448-54.

22. Varma JS, Smith AN, Busuttil A. Function of the anal sphincters after chronic radiation injury. Gut 1986;27:528-33.
23. Beppu N, Kimura H, Matsubara N, Tomita N, Yanagi H, Yamanaka N. Long-term functional outcomes of total mesorectal excision following chemoradiotherapy for lower rectal cancer: stapled anastomosis versus intersphincteric resection. Dig Surg 2016;33: 33-42.

24. Machado M, Nygren J, Goldman S, Ljungqvist O. Similar outcome after colonic pouch and side-to-end anastomosis in low anterior resection for rectal cancer: a prospective randomized trial. Ann Surg 2003;238:214-20.

25. Wallner C, Lange MM, Bonsing BA, Maas CP, Wallace CN, Dabhoiwala NF, et al. Causes of fecal and urinary incontinence after total mesorectal excision for rectal cancer based on cadaveric surgery: a study from the Cooperative Clinical Investigators of the Dutch total mesorectal excision trial. J Clin Oncol 2008;26:446672.

26. Matzel KE, Stadelmaier U, Muehldorfer S, Hohenberger W. Continence after colorectal reconstruction following resection: impact of level of anastomosis. Int J Colorectal Dis 1997;12:82-7.

27. Ogiso S, Yamaguchi T, Hata H, Fukuda M, Ikai I, Yamato T, et al. Evaluation of factors affecting the difficulty of laparoscopic anterior resection for rectal cancer: "narrow pelvis" is not a contraindication. Surg Endosc 2011;25:1907-12.

28. Kim S, Jung SH, Kim JH. Ileostomy versus fecal diversion device to protect anastomosis after rectal surgery: a randomized clinical trial. Int J Colorectal Dis 2019;34:811-9. 